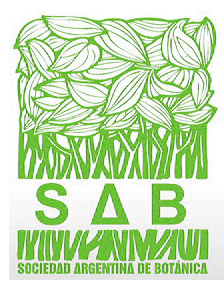

\section{Novedades en el género Schinus (Anacardiaceae): DELIMITACIÓN DE SCHINUS POLYGAMA Y DESCRIPCIÓN DE UNA NUEVA ESPECIE, SCHINUS TALAMPAYA}

\author{
New Findings in Schinus (ANACARDiAceAe): DELIMITATION OF Schinus \\ POLYGAMA AND DESCRIPTION OF THE NEW SPECIES, SCHINUS TALAMPAYA
}

1. Cátedra de Plantas Vasculares. Facultad de Ciencias Naturales. Universidad Nacional de Salta. Avda. Bolivia 5150, 4400, Salta, Argentina.

*marielafabbroni@gmail.com

\section{Citar este artículo}

FABBRONI, M. \& M. A. ZAPATER CANO. 2021. Novedades en el género Schinus (Anacardiaceae): delimitación de Schinus polygama y descripción de una nueva especie, Schinus talampaya. Bol. Soc. Argent. Bot. 56: 201-216.

DOI: https://doi. org/10.31055/1851.2372.v56. n2.31297

Recibido: 11 Dic 2020

Aceptado: 13 Abr 2020

Publicado en línea: 20 Feb 2021

Publicado impreso: 30 Jun 2021

Editor: Franco Ezequiel Chiarini iD

ISSN versión impresa 0373-580X

ISSN versión on-line 1851-2372

\author{
Mariela Fabbroni ${ }^{1 *}$ (D) María A. Zapater Cano ${ }^{1}$ D
}

\section{SUMMARY}

Background and aims: Schinus polygama (Anacardiaceae) has historically been a taxon of intricate taxonomy. It was erroneously considered as a species widely distributed in the Southern Cone. This work intends the delimitation of S. polygama, to describe $S$. talampaya (sp. nov.), previously mistaken with $S$. polygama and $S$. longifolia, and to establish their geographic distribution in Argentina.

M\&M: We revised collections of national and international herbaria, as well as newly collected materials. We consulted the pertinent protologues and specialized taxonomic literature.

Results: Schinus polygama has been delimited from its closely related counterparts. We described a new species: Schinus talampaya. The new species can be distinguished by the shape and size of leaves, type and length of the inflorescence, number of flowers per node, pedicel length, and geographic distribution. Schinus polygama is restricted to Mendoza province in Argentina, while S. talampaya inhabits the provinces of La Rioja and San Juan. We provide pictures, an illustration, a comparative table with morphological data, an identification key, and distribution maps. We discuss the taxonomic placement of the involved taxa among Schinus sections.

Conclusions: The morphological differences between S. polygama and S. talampaya allowed us to place the two species in two different sections: Duvaua and Pilifera, respectively. The new species is an important addition to sect. Pilifera from a morphological point of view, which implies the redefinition of the defining characteristics of the section, and thus the infragenerics systematics of Schinus.

\section{KEY wODS}

Anacardiaceae, Argentina, Schinus, simple leaves, spinescent, taxonomy.

\section{RESUMEN}

Introducción y objetivos: Históricamente Schinus polygama (Anacardiaceae), un taxón de taxonomía compleja y confusa, fue considerado de manera errónea como una especie con una muy amplia distribución en el Cono Sur americano. Este trabajo pretende delimitar S. polygama; describir una nueva especie, Schinus talampaya, confundida con S. polygama y S. longifolia y establecer para ambas su distribución geográfica en la Argentina.

M\&M: Se revisaron colecciones de herbarios nacionales e internacionales y nuevos ejemplares coleccionados. Se consultaron protólogos y trabajos taxonómicos específicos.

Resultados: Se delimitó a S. polygama y se describe una nueva especie: Schinus talampaya, diferenciada por la forma y tamaño de las hojas, tipo y longitud de la inflorescencia, número de flores por nudo, longitud del pedicelo y su distribución geográfica. En la Argentina S. polygama está restringida a la provincia de Mendoza, mientras S. talampaya crece en las provincias de La Rioja y San Juan. Se proveen fotografías, una ilustración, una tabla morfológica comparativa, una clave para las especies afines y un mapa de distribución. Se discute la posición taxonómica de ambos taxones en las secciones del género.

Conclusiones: Las diferencias morfológicas entre S. polygama y S. talampaya permitieron ubicar estas dos especies en diferentes secciones: Duvaua y Pilifera respectivamente. La nueva especie aporta a la variabilidad morfológica de la Sección Pilifera, lo que supone una redefinición de las características morfológicas del grupo y por ende su circunscripción infragenérica.

\section{Palabras claves}

Anacardiaceae, Argentina, espinescente, hojas simples, Schinus, taxonomía. 


\section{INTRODUCCIÓN}

El género Schinus L. es el de mayor magnitud de la Familia Anacardiaceae por el elevado número de especies. Fue dividido infragenéricamente por Barkley (1944) en dos subgéneros: Duvaua (Kunth) F. A. Barkley con hojas simples, inflorescencias en pseudoracimos y tallos espinescentes o no y Euschinus F. A. Barkley con hojas compuestas, inflorescencias mayormente panículas y tallos no espinescentes. Recientemente Silva Luz et al. (2019) plantean una nueva clasificación infragenérica con base en estudios filogenéticos, morfoanatómicos y biogeográficos. El taxón Amyris polygama Cav. fue descripto e ilustrado por Cavanilles (1794) aunque erróneamente lo incluyó en la Familia Rutaceae. Dicha descripción original se basa en ejemplares cultivados en el Regio Horto Matritense a partir de materiales provenientes de Chile. La lámina (Tab. 239), mencionada en el protólogo, ilustra dos ramas separadas, a la izquierda una rama estaminada con abundantes flores e inflorescencias y a la derecha una pequeña rama fructífera. En la parte basal se ilustran flores masculinas, femeninas y frutos. El protólogo, menciona además la existencia de flores hermafroditas, lo que no se encuentra ilustrado. Posteriormente, Ortega (1798) describió las plantas del Regio Horto Matritense estudiadas por Cavanilles, entre ellas a A. polygama a partir de la cual generó un nuevo nombre Schinus dependens Ortega, esta vez clasificándola en la Familia Anacardiaceae. Kunth (1824) describe un nuevo género Duvaua Kunth, caracterizado por poseer hojas simples y flores masculinas y femeninas en individuos diferentes. Así, consideró que las especies $A$. polygama y $S$. dependens eran una única entidad pertenecientes a dicho género y estableció la combinación: Duvaua polygama (Cav.) Kunth. Un año después, de Candolle (1825) transfirió $S$. dependens a Duvaua dependens (Ortega) DC., considerando a A. polygama en su sinonimia. Posteriormente, Marchand (1869) subdividió al género Schinus en dos Secciones: Euschinus y Duvaua, incluyendo en esta última a $S$. dependens, con tres variedades basadas en el tamaño de las hojas y flores. Una de ellas es $S$. dependens var. parviflorus Marchand, cuyo tipo es un espécimen colectado en Bolivia. Luego, Cabrera (en Frenguelli, 1937) publicó la combinación Schinus polygamus (Cav.) Cabrera respetando el principio de prioridad y considerando a $S$. dependens y A. polygama como sinónimos. Un año después (1938) consideró que el taxón S. polygamus f. parviflorus Marchand corresponde al subgénero Duvaua, categoría que el autor no formalizó. Luego Barkley (1944), en su monografía del género Schinus, propuso el subgénero Duvaua (Kunth) Barkley, caracterizado por ser arbustos y pequeños árboles, inermes o no, con hojas simples, inflorescencias en pseudoracimos (seudoflorescencia, con eje principal indeterminado y ramificaciones laterales cimosas sin completar su desarrollo (Rúa, 1999) o raramente panículas pequeñas, que habitan en el sur de América del Sur. El mismo autor subdividió al subgénero Duvaua en secciones, entre ellas la Sección Euduvaua con S. polygamus como especie tipo. Para esta última consideró tres variedades, var. polygamus, var. chilensis Barkley y var. parviflorus (Marchand) Barkley, con base en el tamaño de la inflorescencia y la morfología foliar, aunque reconoció la existencia de individuos intermedios. Posteriormente, Barkley (1957) redujo las variedades al sinonimizar la var. chilensis con la var. polygamus. Este criterio de delimitación taxonómica para el taxón se mantiene hasta la actualidad sin variantes. En recientes estudios sobre la filogenia del género Schinus, Silva Luz (2017) y Silva Luz et al. (2019) proponen ocho secciones, entre ellas, la Sección Duvaua (Kunth) Marchand a la que consideran polifilética y en la que incluyen a $S$. polygama (como especie tipo) y sus dos variedades; además de $S$. latifolia (Gillies \& Lindl.) Engl. y S. velutina (Turcz.) I. M. Johnst.

Otro importante aspecto a considerar es la distribución geográfica y biogeográfica de $S$. polygama, ya que varios autores mencionan que la especie habita en varios países latinoamericanos, como Brasil (Engler, 1876; Cabrera, 1938; Barkley, 1944; Fleig, 1985), Uruguay (Arechavaleta, 1901; Cabrera, 1938), Bolivia (Marchand, 1869; Barkley, 1957), Perú (Barkley, 1944; Macbride, 1951), además de la Argentina y Chile Central (Cabrera, 1938; Barkley, 1944, 1957; Muñoz, 2000; Martínez Carretero, 2009). Para la Argentina se la citó más recientemente para las provincias de Mendoza (Dpto. Tunuyán) (Muñóz, 2000, Silva Luz et al., 2019), San Juan (Múlgura, 2003; Martínez Carretero, 2009), La Rioja (Barboza et al., 2016) y Catamarca (Perea et al., 2007).

Desde la descripción de $S$. polygama se le atribuyó erróneamente el nombre de este taxón 


\section{Fabbroniy M. A. Zapater Cano - Delimitación de S. polygama y descripción de nueva especie}

a entidades diferentes (Cabrera, 1938; Johnston, 1938; Barkley, 1957; Steibel \& Troiani, 2008; entre otros), lo que coincide con lo expuesto por Muñoz (2000).

Para la Flora chilena se reconoce a S. polygama como una entidad sin taxones infraespecíficos (Rodríguez et al., 2018). Sin embargo, Silva Luz et al. (2019) refuerzan la delimitación de la var. parviflora y señalan la necesidad de mayores estudios para definir con mayor certeza la variabilidad infraespecífica, incluyendo la distribución geográfica y los hábitats que ocupan como línea adicional de evidencia. Por otra parte, al encontrarse publicaciones y materiales de San Juan, La Rioja y de otras provincias identificados erróneamente como S. polygama, se considera necesario delimitar esta especie de otras especies afines del género Schinus, con base en sus caracteres morfológicos para una certera identificación de sus individuos. Además, debido a la amplia distribución geográfica y biogeográfica documentada para Sudamérica y en particular en la Argentina y a los numerosos nombres científicos atribuidos a $S$. polygama, es necesario esclarecer la identidad de este taxón y de los otros taxones. Por lo expuesto, los objetivos que se plantean en esta investigación son: i) resolver problemáticas taxonómicas infraespecíficas y nomenclaturales en $S$. polygama; ii) describir una nueva entidad del género, hasta ahora considerada como S. polygama, y iii) actualizar la distribución geográfica en Argentina de las dos especies estudiadas con base en su biogeografía.

\section{Materiales y Métodos}

Se estudiaron colecciones de la Argentina y Chile existentes en los Herbarios CTES, LIL, MCNS, MERL y SI (acrónimos según Thiers, actualización permanente), además de materiales propios coleccionados en la provincia de $\mathrm{La}$ Rioja. Se consultaron imágenes virtuales tanto de ejemplares tipo como de materiales adicionales (disponibles en la base de datos Jstor Global Plants) de los Herbarios: E, K, MA, MO, NY, P y SPF. Para las descripciones de los taxones se siguió la terminología de Moreno (1984). Las observaciones y fotografías se realizaron con un microscopio estereoscópico (Zeiss DVA4) y con la cámara Cannon PowerShot 20MP. Se consultaron los protólogos de $S$. polygama, sus variedades y de cada uno de los taxones incluidos en su sinonimia. Para la tipificación se consultó el Código Internacional de Nomenclatura para Algas, Hongos y Plantas (Código de Shenzhen) (Turland et al., 2018). Para definir el nuevo taxón se analizaron comparativamente todos los caracteres exomorfológicos de materiales propios y de herbario disponibles. También se analizaron las figuras publicadas en la Flora de San Juan (Múlgura, 2003) y las fotografías de la Flora de Catamarca (Perea et al., 2007) bajo el nombre $S$. polygama. El mapa de distribución de las especies se realizó con el programa QGIS (2018) utilizando las coordenadas de los nuevos ejemplares de herbario y para las colecciones existentes se estimaron las coordenadas a partir de los datos de las tarjetas de herbario.

\section{Resultados}

\section{Tratamiento Taxonómico}

Schinus polygama (Cav.) Cabrera. Rev. Mus. La Plata (Obra del Cincuentenario) 2: 269. 1937. Amyris polygama Cav. Icones 3: 20-21, Tab. 239. 1794. TIPO: CHILE, sin loc., cultivado en Madrid (España) en el Hortus Regis Matritensis, 1794, (Lectotipo, aquí designado, Tab. 239!; Epitipo, aquí designado, MA 475389!) Fig. 1A, B.

= Schinus dependens Ortega. Hort. Matr. 8: 102103. 1798. nom. illeg.

= Duvaua ovata Lindl. Edward's Bot. Reg. 19. 1833. TIPO: Sin colector (Lectotipo, aquí designado, K000695367!).

= Schinus polygamus var. chilensis Barkley. Brittonia 5: 175. 1944. TIPO: Johnston 6275 (Holotipo GH, no visto).

Árboles y arbustos dioicos de hasta 1,5(3) m alt. Ramas adultas grisáceas o castañas, estriadas, lenticelas ovadas a circulares, castañas (Fig. 1C); en las menores de 3 años de 0,25-0,65 cm diám. a la base, se originan las ramas espinescentes del año a $45^{\circ}, 60^{\circ}$ raro $90^{\circ}$ de $1-9(21)$ x $0,1-0,5 \mathrm{~cm}$ diám. a la base, rojizas, ascendentes. A veces se encuentran ramas espinescentes largas de aprox. $16 \mathrm{~cm}$ long. 

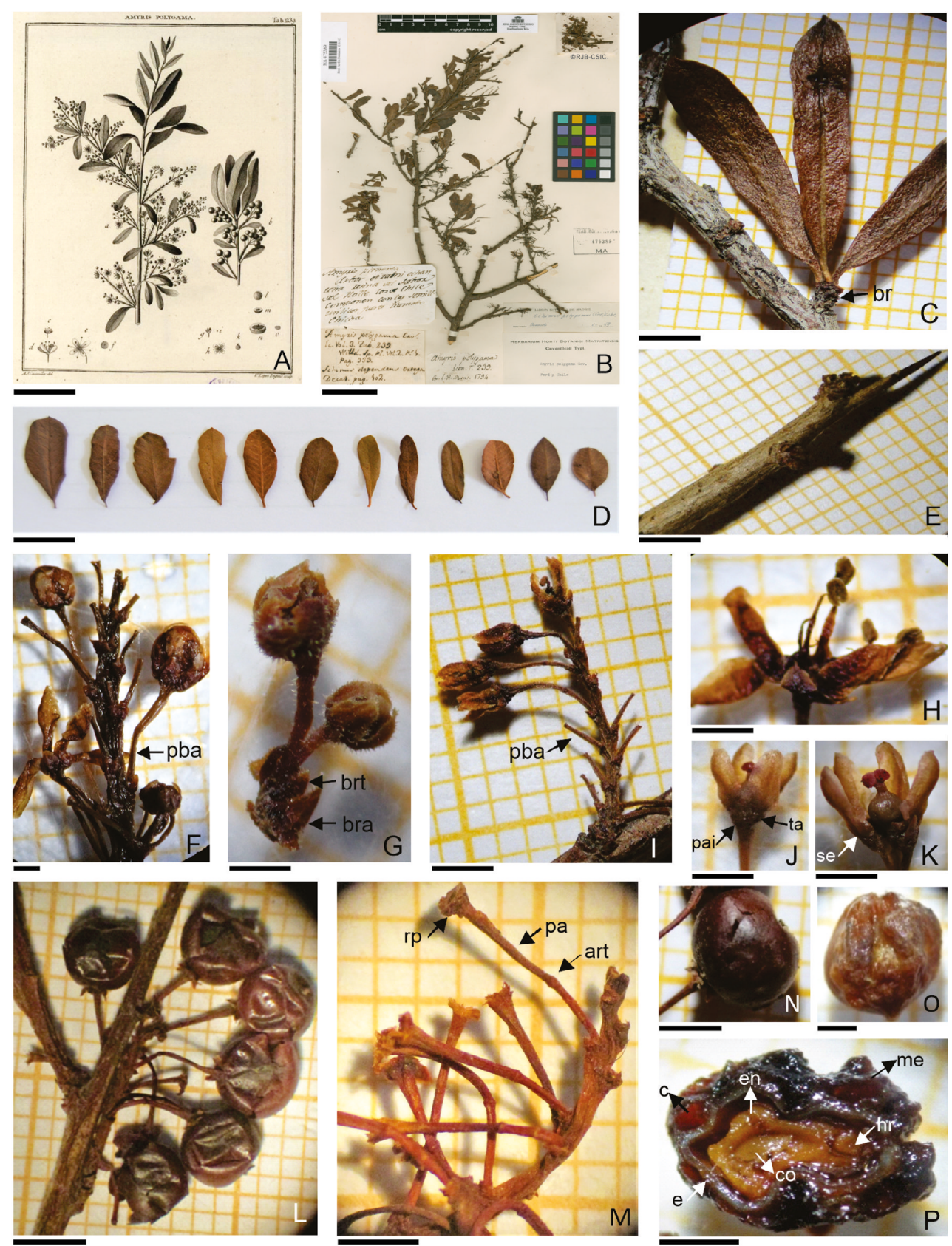

Fig. 1. Schinus polygama. A: Lectotipo. B: Epitipo. C: Rama vegetativa. D: Variabilidad de hojas. E: Rama espinescente F: Tirso masculino. G: Nudo con dos flores masculinas jóvenes. H: Flor masculina madura. I: Tirso femenino. J-K: Flor femenina. L: Rama fructífera. M: Pedicelos fructíferos. N: Fruto maduro. $\mathbf{O}$ : Mesocarpo. P: Transcorte del fruto. Abreviaturas= art: articulación; br: braquiblasto; bra: bráctea; brt: bracteóla; c: conducto resinífero; co: cotiledones; e: endocarpo; en: endosperma; hr: eje hipocótilo-raíz; m: mesocarpo; pa: pedicelo articulado; pai: pedicelo apical infundibuliforme; pba: pedicelo basal articulado; rp: restos pertiánticos; se: sépalo; ta: tálamo. Escalas=A, B: $5 \mathrm{~cm} ; \mathrm{C}, \mathrm{E}: 3,3 \mathrm{~mm} ; \mathrm{D}: 2,8 \mathrm{~cm} ; \mathrm{F}, \mathrm{K}, \mathrm{P}: 1 \mathrm{~mm}$; G: 0,8 mm; H, J: 1,2 mm; I: 2,1 mm; L: $3 \mathrm{~mm}$; N N: $2 \mathrm{~mm}$; O: 0,7 mm. A: Icones 3, Tab. 239; B: Herbario del Real Jardín Botánico, CSIC, Madrid (MA 475389); C, E, N: Covas 1776; F, I: Werdermann 85; G: Biese 1918; H, J, K: Biese 168; L, M, P: Ruiz Leal 2111; O: Kausell 1662. 


\section{Fabbroniy M. A. Zapater Cano - Delimitación de S. polygama y descripción de nueva especie}

y sobre ellas se originan otras ramas espinescentes cortas de 1-2,3 cm long. Hojas simples, láminas de $(1,4) 2-3,2 \times 0,4-1(1,9) \mathrm{cm}$, alternas, obovadas, elípticas y ovadas, a veces lanceoladas, subcoriáceas a coriáceas, glabras; nervio principal y secundarios evidentes en el envés hasta el $1 / 3$ apical, luego atenuados; margen entero, a veces con 2-3(4) dientes en la mitad superior o festoneado; ápice agudo o mucronado, a veces obtuso; base atenuada, cuneada, raro redondeada (Fig. 1D); pecíolo de (1)2-5 mm long., acanalado, el margen a veces con reborde engrosado más claro, glabro o con pequeños tricomas esparcidos. Hojas obovadas más largas en las ramas apicales del año con desarrollo vegetativo predominante y peciolos de $5 \mathrm{~mm}$; hojas más cortas en las ramas floríferas con pecíolos de $2 \mathrm{~mm}$ long. En una rama florífera espinescente se forman de 2 a 8 tirsos. A menudo también se forman pequeños braquiblastos de (1,1)3-6 x 1-3 mm (Fig. $1 \mathrm{E})$, más o menos abundantes, rojizos a castaños con 1-3(4) hojas basales y tirsos apicales, aunque algunos individuos pueden no formar braquiblastos. Tirsos masculinos laxos (Fig. 1F), reunidos de hasta tres en las axilas foliares con 2-3(4) flores por nudo (Fig. 1G) y 11-38 flores por tirso; raquis de $(0,4) 1,2-2(2,4)$ x $0,03-0,1 \mathrm{~cm}$, costillado y parcialmente aplanado y adelgazado hacia el ápice, con entrenudos de 0,5-2 mm, glabro, a veces con algunos tricomas dorados, esparcidos; brácteas de $0,4-0,8 \times 0,5-0,8 \mathrm{~mm}$, rojizas a castaño oscuras, triangulares, con márgenes superiores ciliados, dorados y a veces con tricomas en forma de pelos en el dorso (Fig. 1G); en su interior se encuentran dos bractéolas por flor, de 0,4-1,5 x 0,2-0,3 mm, ovadas, castaño claras y con márgenes superiores ciliados, a veces las bractéolas se disponen en la mitad de la porción basal del pedicelo. Flores tetrámeras, a veces pentámeras en la misma planta. Flores masculinas de 2-3 mm cuando maduras (Fig. $1 \mathrm{H})$, opuestas a subopuestas; pedicelo articulado de 2,6-4,6 mm long. con disco de abscisión notable más o menos oscuro y engrosado, pedicelo basal de 1,1-2,4 mm con pubescencia esparcida, pedicelo apical de 1,5-2,2 $\mathrm{mm}$ con pubescencia semidensa $\mathrm{y}$ el ápice ensanchado infundibuliforme de $0,3 \mathrm{x}$ $0,5 \mathrm{~mm}$, translúcido, en cuyo interior se continua el eje central del pedicelo hasta la base del tálamo. Cáliz de 0,7-1 x 0,5-0,8 mm, sépalos triangulares, con nervio central oscuro, margen irregularmente ciliado hacia el ápice, glabros, a veces pubescentes solo en el haz. Corola de 2,5-3 x 1-2 mm, pétalos blanquecinos, obovados, cuculeados, translúcidos, con nervio central oscuro y margen irregular. Androceo con 8-10 estambres de 1,6-2,7 mm long. en 2 ciclos desiguales (Fig. 1H), filamentos de 0,5-2 $\mathrm{mm}$ long., ensanchados en la base, anteras de 0,5$0,8 \times 0,3-0,5 \mathrm{~mm}$, disco interestaminal lobulado de $0,5 \mathrm{~mm}$ alt. Pistilodio de $0,7 \times 0,2-0,3 \mathrm{~mm}$, ovoide, con estilo largo y tres estigmas incipientes. Tirsos femeninos laxos con 1-2(3) flores por nudo y (7)1019(24) flores por tirso (Fig. 1I), uno por nudo en la axila foliar, a veces sobre cortos braquiblastos en las ramas jóvenes espinescentes, raros en ramas adultas no espinescentes; raquis de $(0,2) 0,7-1,4 \times 0,07-0,08$ $\mathrm{cm}$, no cubierto por brácteas, entrenudos de $0,5-1,5$ $\mathrm{mm}$ long., ancho en la base y delgado hacia el ápice, glabro, muy raro con tricomas esparcidos; flores subopuestas en nudos muy cercanos, en la axila de una bráctea de $0,6-0,8 \times 0,4-0,5 \mathrm{~mm}$, deltoide, rojiza o castaña, de margen ciliado y entre dos bractéolas basales, de 0,4 x 0,2 mm, romboides y ciliadas en el ápice. Flores femeninas de 1,5-1,8 mm (Fig. 1J, $\mathrm{K}$ ), con pedicelo articulado de 2-6 mm, apicalmente ensanchado, infundibuliforme, dividido por un disco de abscisión demarcado y engrosado que a menudo no abscisiona en el proceso de fructificación; ambos pedicelos pueden diferenciarse o no en grosor, longitud, color y pilosidad. El pedicelo superior de 1,5-3 mm, a menudo es esparcidamente pubescente, raro glabro; el basal de 1-3,5 mm es generalmente glabro, a veces con pubescencia rala. Cáliz de $0,4-$ $0,5 \times 0,5-0,6 \mathrm{~mm}$, con sépalos triangulares (Fig. $1 \mathrm{~K})$, cortamente pubescentes en el dorso, margen translúcido y ciliado con tricomas translúcidos. Corola de 1,4-2 x 0,5-0,7 mm, pétalos obovados y elípticos, blanquecinos a amarillentos, translúcidos, glabros. Androceo con 8-10 estaminodios de hasta $0,8 \mathrm{~mm}$, filamentos delgados y translúcidos de 0,2-0,5 mm, anteras de 0,1-0,3 x 0,1 mm, disco interestaminal de $0,3 \mathrm{~mm}$ alt. con bordes engrosados. Ovario de 0,5-0,6 x 0,7-0,8 mm, obovado (Fig. 1K), con tricomas más o menos abundantes con forma de pelos y glandulares, estilo curvo de $0,3 \times 0,2 \mathrm{~mm}$ con tricomas translúcidos dispersos y tres ramas estilares descendentes de $0,015 \mathrm{~mm}$ diám. que rematan cada una en una cabeza estigmática globosa de $0,025 \mathrm{~mm}$ diám. Drupa de 3,5-4 x 4-4,5 mm, globosa, obovoide o umbilicada, rojiza, rosada a púrpura (Fig. 1L), con el cáliz persistente sobre un pedicelo fructífero de 4-6,8 mm (Fig. 1M, N); exocarpo delgado, friable, 
con tricomas cortos y glandulares semidensos; mesocarpo de 0,25-0,55 mm lat., externamente con costillas poco pronunciadas no uniformes, a menudo con protuberancias sobre las costillas (Fig. 1O), interiormente con conductos resiníferos de 0,5-0,6 $\mathrm{mm}$ lat. (Fig. 1P). Hacia el interior se encuentra el endocarpo del tipo Anacardium con tres capas de esclereidas en empalizada de $0,12 \mathrm{~mm}$ de espesor en total, con lóbulos marcados (Fig. 1P). Semilla de 1,8-3,3 x 1,3 x 2,2 mm, exalbuminada, con cotiledones de 1-2 x 1,1-1,3 mm en corte transversal (Fig. 1P).

Distribución geográfica y biogeográfica. En la Argentina posee una distribución restringida a la provincia de Mendoza en el Dpto. Tunuyán, en la región de Cuyo, concordante con Muñóz (2000) y Silva Luz et al. (2019) (Fig. 2). En Chile presenta una extensa distribución desde el Norte Grande (Región de Atacama) hasta la Región de los Lagos al sur ocupando un amplio rango latitudinal: $28^{\circ} 32^{\prime}$ $39^{\circ} 31^{\prime}$ y altitudinal: 0-3200 msnm con diversidad de hábitats (Rodríguez et al., 2018). Sus poblaciones se encuentran en las Provincias Fitogeográficas del Desierto y la Chilena Central (Cabrera \& Willink, 1973), siendo frecuente en el matorral esclerófilo, tanto en planicies como en laderas; preferentemente sobre suelos pobres y áridos de exposición norte (Cortez-Echeverría, 2016; Silva Luz et al., 2019). En la Argentina se encuentra en la Provincia Fitogeográfica del Monte (Morrone, 2004; Oyarzábal et al., 2018). En particular, habita en un sector del Cordón del Plata y en el Piso de los Matorrales Andinos Húmedos, con altitudes entre los 1400 a $2600 \mathrm{msnm}$, que se asientan sobre los faldeos de cerros preandinos y pedemontes con cauces temporarios, asociados a suelos permeables, arenosos a francos. También crece en embanques de quebradas húmedas y umbrías donde predomina el clima desértico con precipitaciones medias anuales entre $300-400 \mathrm{~mm}$, principalmente en forma de nieve, entre las isohietas de $10^{\circ}-15^{\circ} \mathrm{C}$ (Roig \& Ambrosetti, 1971; Ambrosetti, 1972; Méndez, 2011).

Nombres vernáculos. "Molle, molle de incienso". En Chile "huingán" (Rodríguez et al., 2018).

Fenología. Florece desde octubre a diciembre y mantiene sus frutos en la planta hasta el mes de junio.

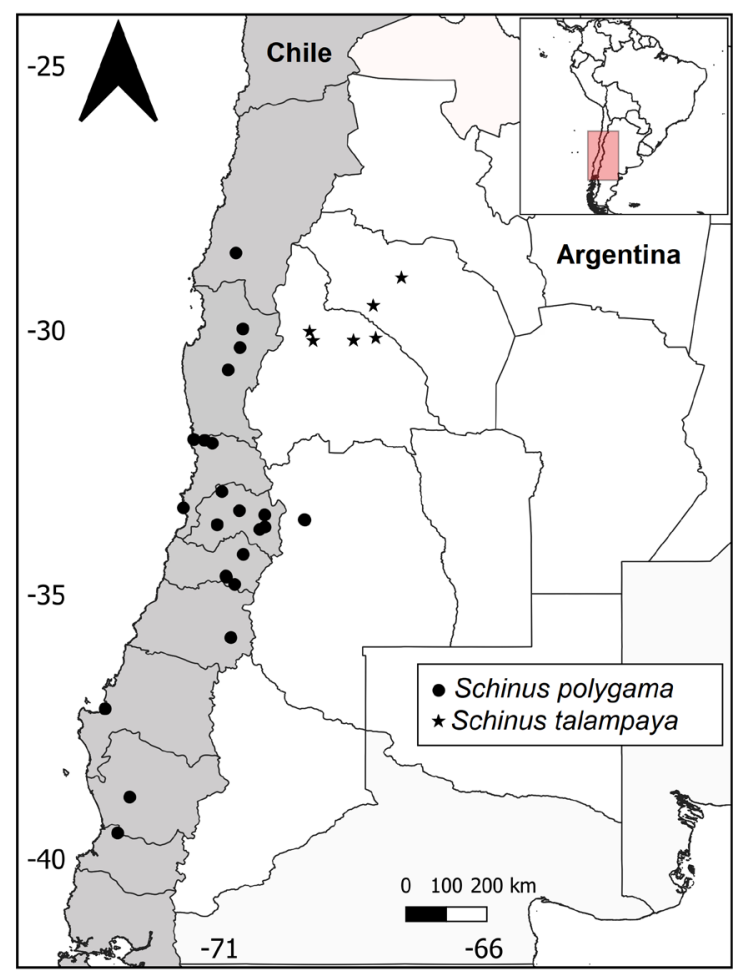

Fig. 2. Distribución geográfica de Schinus polygama y S. talampaya en Argentina y Chile.

Usos. En medicina popular el fruto se emplea en la preparación de chicha y aguardiente por sus favorables propiedades antimicrobianas (WilhelmMösbach, 1992; Hoffmann, 1995; Erazo et al., 2006). Posee hojas con propiedades analgésicas y antiinflamatorias y en mayor cantidad en sus frutos (Cortéz-Echeverría, 2016). En Mendoza se cultiva en plazas (Martínez Carretero, 2009). En Chile se emplea para reforestación de áreas afectadas por incendios (Corporación Cultiva, 2018).

Material estudiado. ARGENTINA. Prov. Mendoza: Dpto. Tunuyán, Camino al Paso de los Puntanos, 29-I-1939, Ruiz Leal 2111 (LIL); El Manzano, 12-VI-1944, Covas 1776 (LIL). CHILE. III Región: Atacama, Prov. Huasco, Valle de Huasco, Chañar Blanco, 13-X-1984, Zöllner 12070 (MO). IV Región: Coquimbo, Prov. Choapa, Illapel, Desvío Pola hasta Tunel, 12-X-1945, Biese 1918 (LIL); Los Vilos, Fundo Palo Colorado, quebrada Del Buitre, 14-X-1948, Kausel 2643 (LIL); Quilimari, Maimalicán, 13-X-1948, Kausel 2633 (LIL). Prov. 


\section{Fabbroniy M. A. Zapater Cano - Delimitación de S. polygama y descripción de nueva especie}

Elqui, Rivadavia, XI-1923, Werdermann 85 (LIL, SI). Prov. Ovalle, Chilecito, 28-IX-1947, Jiles 511 (LIL); Quebrada la Embarrada, Hacienda El Bosque, 29XI-1939, Wagenknecht 18488 (LIL, MO). V Región: Valparaíso, Prov. Valparaíso, Algarrobo, playa El Canelo, 15-26-II-1950, Kausel 3094 (LIL, NY). VI Región: O'Higgins, Prov. Colchagua, Puente Negro, 31-XII-1950, Ricardi 926 (LIL); río Claro, 1-I-1951, Ricardi 944 (LIL); San Fernando, Talcarehue, 30XII-1950, Ricardi 919 (LIL). Prov. Rancagua, Terma de Cauquenes, 3-XI-1952. Pfister 13153 (LIL). VII Región: Maule, Prov. Talca, San Clemente, Rodovia 115 en dirección a la frontera con Argentina, próximo al Km 107, 22-IX-2013, Silva Luz 198 (SPF). VIII Región: Bío Bío, Prov. Arauco, Laraquete, 15-XII1950, Ricardi 744 (LIL). IX Región: Araucanía, Prov. Cautín, río Quepe, 2-II-1942, Kausel 1005 (LIL). XIV Región: Los Ríos, Prov. Valdivia, San José de la Mariquina, III-1926, Werdermann 1191 (LIL, MO). Región: Metropolitana de Santiago, Prov. Santiago, Las Condes, rio Yeso, 18-XI-1944, Biese 168 (LIL); Cerro San Cristóbal, 31-X-1948, Kausel 2681 (LIL); ídem, 18-IX-2013, Silva Luz 192 (SPF); Cord. de Santiago, 15-II-1923, Werdermann 486 (LIL); Cuesta de la Dormida, 8-III-1951, Sudzuki et al. 21 (LIL); El Paico, III-1938, Kausel 389 (LIL); Valle del Maipo, San Gabriel, 14-X-1945, Kausel 1662 (LIL); ídem, sin fecha, Gillies 74 (E).

Observaciones. 1) Se designó como lectotipo a la lámina Tab. 239 mencionada en el protólogo y considerado material original según el Art. 9.4 del Código de Shenzhen (Turland et al., 2018). Por otra parte se designó un epitipo (MA 475389) (Art. 9.9) para apoyar la identificación del taxón teniendo en cuenta que la especie es dioica, el material seleccionado representa a una rama femenina del Herbario MA y, fue estudiado por Cavanillies para la descripción original en el mismo año. Este espécimen contiene una etiqueta manuscrita por el autor con la siguiente leyenda: “Amyris polygama, Icon. T239, Ex. h. R. Matrit. 1794" (Garilleti, 1993) (Fig. 1B).

2) En el caso de Duvaua spinescens Tenore se descarta de la sinonimia porque el ejemplar tipo (Tenore s.n. K000695368) visto en Jstor Global Plants no corresponde a S. polygama, debido a que la morfología foliar no es concordante y por otra parte es un material estéril. En las actuales condiciones del ejemplar no es posible proponer una sinonimia con respecto a otro taxón.
3) En algunos individuos pueden no desarrollarse braquiblastos y es más o menos frecuente la presencia de tirsos caulifloros. En el pedicelo articulado se observó una reducida abscisión en el disco al estado floral, tanto en individuos femeninos como masculinos. En estado de fructificación y maduración del fruto, es muy común que el disco no produzca abscisión por lo que no participa en la dispersión del fruto, el que se dispersa sin acompañamiento del perianto que permanece en el extremo del pedicelo articulado (Fig. 1M).

4) Schinus polygama es considerada un superhospedero de insectos irritantes pertenecientes a los grupos Diptera (Cecidomyiidae), Hemiptera (Psylloidea) y Lepidoptera (Cecidosidae) (Sáiz \& Núñez, 1997; Burckhardt \& Basset 2000; Guedes et al., 2018).

Schinus talampaya M. Fabbroni \& Zapater, sp. nov. TIPO: ARGENTINA, Prov. San Juan, Dpto. Valle Fértil, Agua de la Peña, Ischigualasto, 26-V-1959, A. R. Cuezzo 2941 (Holotipo LIL 502298!, Isotipo LIL 464158!). Figs. 3 y 4.

Spinescent shrub, linear to oblanceolate leaves, one veined, blade 2.2-5.5 $\times 0.1-0.4 \mathrm{~cm}$, inflorescence pseudoraceme congested, with axis covered by bracts, with 2-9 flowers and one flower per node, pentamerous flowers, pedicel 1-2.4 mm long, articulated, abscission disk not conspicuous, reddish-brown drupe, 5.1-5.7 x 5-6.4 mm, not spherical, umbilicate.

Arbusto dioico, perennifolio de 2-2,5 m alt. con varias ramificaciones basales de 3-6 cm diám., copa irregular. Ramas adultas, grisáceas, estriadas, glabras (Fig. 3A, B), lenticelas ovadas, castañas y abundantes; ramas terminales espinescentes, de 2,5-10 × 0,1-0,4 cm diám., rojizas (Figs. 3C; $4 \mathrm{~A}$ ), dispuestas a $45^{\circ}, 60^{\circ}$ raro a $90^{\circ}$ sobre ramas de mayor edad, ascendentes, glabras. Hojas simples, láminas de 2,2-5,5 x 0,1$0,4 \mathrm{~cm}$, lineares a oblanceoladas, a veces falcadas, alternas (Fig. 3D), uninervias (Figs. 3E; 4B), margen entero, ápice agudo, mucronado a veces retuso, base cuneada y atenuada a veces decurrente, glabras; pecíolo de 1-3(3,5) mm long., acanalado, glabro. En una rama florífera espinescente se forman de 2-7 inflorescencias. Braquiblastos de 1-5 x 1-2 mm, sobre ramas espinescentes, con 1-3(4) hojas en la axila de una bráctea (Fig. 3F), a veces con inflorescencia 

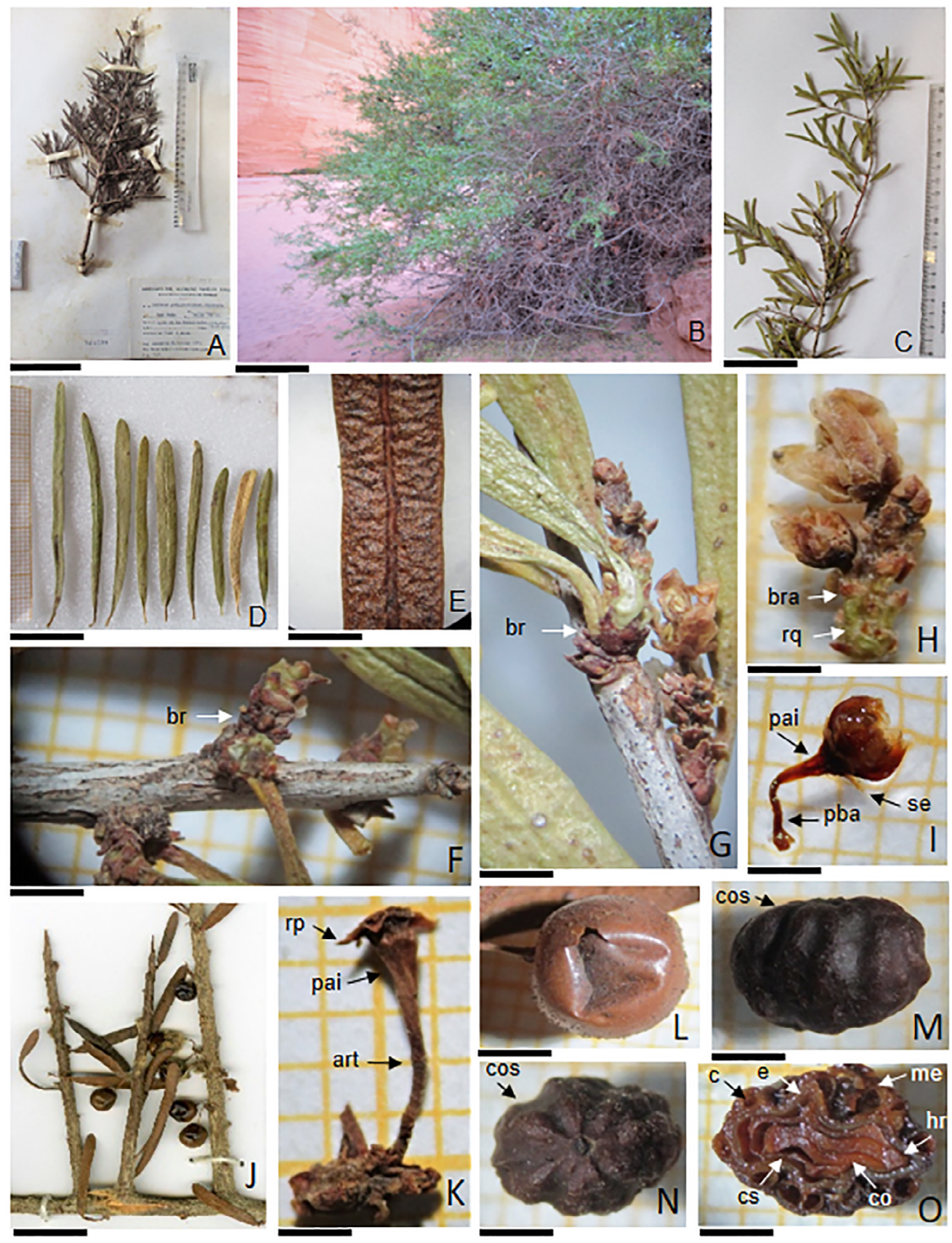

Fig. 3. Schinus talampaya. A: Holotipo. B: Hábito. C: Rama joven. D: Variación de tamaños de hojas. E: Porción de lámina. F: Rama espinescente. G: Pseudoracimos axilares. H: Pseudoracimo masculino. I: Flor masculina. J: Ramas fructíferas. K: Pedicelo fructífero. L: Fruto. M: Vista lateral del mesocarpo. N: Vista superior del mesocarpo. O: Transcorte del fruto. Abreviaturas= art: articulación; br: braquiblasto; bra: bráctea; c: conducto resinífero; co: cotiledones; cos: costilla; cs: cubierta seminal; e: endocarpo; hr: eje hipocótilo-raíz; m: mesocarpo; pai: pedicelo apical infundibuliforme; pba: pedicelo basal articulado; rp: restos periánticos; rq: raquis; se: sépalo. Escalas $=A: 8 \mathrm{~cm}$; $\mathrm{B}: 50 \mathrm{~cm} ; \mathrm{C}: 5 \mathrm{~cm} ; \mathrm{D}, \mathrm{J}: 1,5 \mathrm{~cm} ; \mathrm{E}, \mathrm{G}, \mathrm{N}: 2 \mathrm{~mm}$; F, H, I, K: 1,5 mm; H: $6 \mathrm{~mm}$; K: $7 \mathrm{~mm}$; L: 2,4 mm; M, O: 1,8 mm . A, E, I: Cuezzo 2941; B: fotografía de M. Fabbroni; C, D, F, G, H: Fabbroni \& Gauffin 1341; J: Hunziker 1830; K, L, M, N, O: Castellanos 16828. 

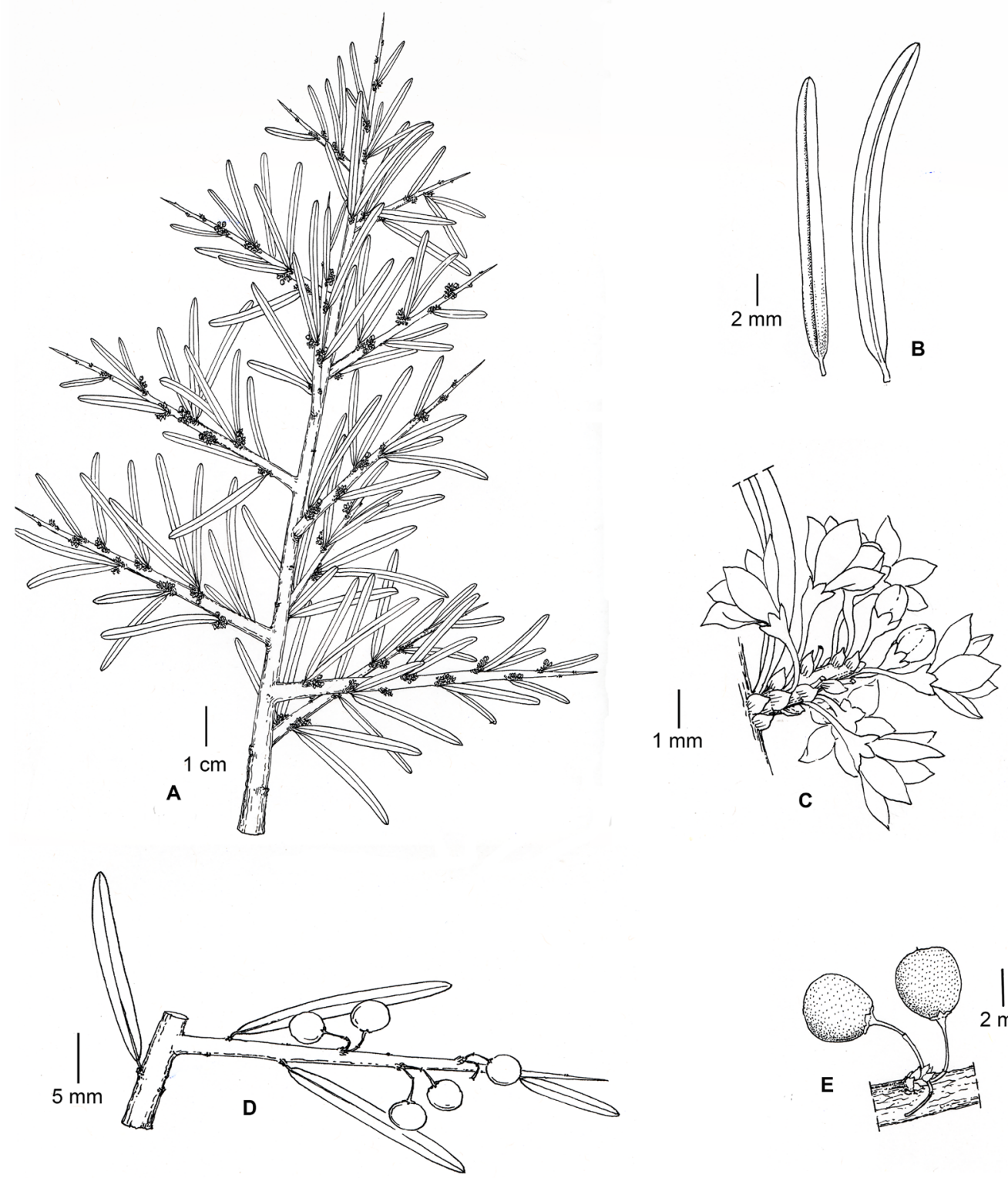

Fig. 4. Schinus talampaya. A: Rama florifera masculina. B: Hojas, haz (izq.) y envés (der.). C: Detalle de un pseudoracimo masculino. D: Rama espinescente con frutos. E: Detalle de frutos maduros. (Cuezzo 2941, Hunziker 1830).

terminal, rojizos a castaños, con entrenudos muy cortos cubiertos con brácteas rojizas, éstas de $0,5 \mathrm{x}$ $0,4 \mathrm{~mm}$, triangulares a deltoides, glabras (Fig. 3G). Inflorescencia masculina en pseudoracimo congesto, sésil, uno por nudo, en la axila de una hoja (Figs. 3G; 4C) o en el ápice de un corto braquiblasto con varias hojas basales, a veces con dos inflorescencias en un braquiblasto; raquis de $(0,1) 0,2-0,4 \times 0,11 \mathrm{~cm}$, semi a totalmente cubierto por brácteas rojizas (Fig. $3 \mathrm{H}$ ), entrenudos de 0,2-0,6 mm long., con 2-9 flores, cada una en la axila de una bráctea triangular a deltoide de ca. 1-2,2 x 0,4-1 mm, margen ciliado y nervio central ancho y marcado, con dos bractéolas en su interior de $0,8 \times 0,2 \mathrm{~mm}$, angostas, ovadas, agudas, con 
margen ciliado. Flores estaminadas, cuando maduras de 2-3 mm con pedicelo articulado, de 1-2,4 mm, variable según las poblaciones, glabro, apicalmente ensanchado, infundibuliforme, dividido por un disco de abscisión en dos zonas (Fig. 3I). Pedicelo basal de 0,4-1,2 x 0,2-0,25 mm, blanquecino en fresco, y el pedicelo superior de 0,6-1,2 x 0,2-0,4 mm, negro brillante en fresco; tálamo infundibuliforme, de 1-2 x $5 \mathrm{~mm}$ (Fig. 3I). Cáliz de 0,7-1 x 0,6-0,8 mm, pentámero, sépalos triangulares, ápice agudo, margen apicalmente ciliado, glabros. Corola de 1,8-2,2 x 1-1,4 mm, pentámera, pétalos ovados a elípticos, blancos, translúcidos con nervio central oscuro, ápice agudo a truncado, margen entero, glabros, reflexos a la madurez. Androceo con 10 estambres en 2 ciclos desiguales, el externo de 1,5-2,1 mm long. y el interno de 1,2-1,3 mm long., filamentos ensanchados, anteras de 0,6-0,7 x 0,3-0,4 mm, disco nectarífero carnoso interestaminal 10-lobulado. Pistilodio sacciforme de $0,5 \times 0,3 \mathrm{~mm}$ con tres estilos y estigmas con hendidura central. Inflorescencia femenina en pseudoracimo similar a la masculina, cada una en la axila de una hoja, con 2-3 flores, una por nudo y raquis de 1-2,8 $\mathrm{mm}$ long. cubierto por brácteas. Flores femeninas no vistas. Drupa de 5,1-5,7 x 5-6,4 mm, umbilicada, no esférica, castaño-rojiza (Fig. 4D, E), con el cáliz persistente sobre un pedicelo fructífero de 2,8-4,2 mm (Fig. 3J, K); exocarpo delgado, friable, con tricomas mayormente glandulares y esparcidos irregularmente (Fig. 3L). Anatómicamente en corte transversal, el fruto se compone de un mesocarpo castaño oscuro, de 0,9-1,25 mm lat., con costillas redondeadas, gruesas, pronunciadas y uniformes, a veces con protuberancias, que se corresponden con los lóbulos del endocarpo y los conductos del mesocarpo (Fig. $3 \mathrm{M}, \mathrm{N}$ ), el cual está revestido exteriormente por resinas secretadas por los conductos del propio mesocarpo; los conductos resiníferos desiguales en tamaño, de 0,3-0,75 mm diám. hacia el interior el endocarpo de 0,2 mm lat., con lóbulos marcados e irregulares y tres capas de esclereidas en empalizada (Fig. 3O). Semilla de 4,5 x 2,2 mm, dos cotiledones largos y delgados de $3,4 \times 0,5 \mathrm{~mm}$ en corte transversal (Fig. 30).

\section{Nombre vernáculo. "Molle".}

Etimología. El epíteto específico hace referencia a uno de los sitios donde esta especie es particularmente frecuente.
Fenología. Se registró la floración desde mayo a setiembre y la fructificación en el verano.

Usos. Colorante, dato extraído de la tarjeta de herbario del ejemplar Stramiglioli 19 (SI).

Distribución geográfica y biogeográfica. Especie endémica de la Argentina, restringida a las provincias de La Rioja (Dptos. Felipe Varela y Famatina) y San Juan (Dptos. Iglesias, Jáchal y Valle Fértil) (Fig. 2), y probablemente también en Catamarca (Dpto. Tinogasta y Antofagasta de la Sierra) teniendo en cuenta algunas fotografías publicadas bajo la denominación de S. polygama (Perea et al., 2007). Habita en las Provincias Fitogeográficas de la Prepuna y del Monte (Cabrera, 1976; Oyarzábal et al., 2018) a lo largo de un amplio rango altitudinal desde los 400 hasta los $2000 \mathrm{msnm}$. Crece en valles angostos y quebradas, como integrante de los bosques ribereños de cursos de agua temporarios y permanentes, sobre suelos sueltos, arenosos y rojizos (Fig. 3B), junto a especies del género Prosopis L., Geoffroea decorticans (Gillies ex Hook. \& Arn.) Burk.; Zuccagnia punctata Cav., Larrea cuneifolia Cav. y plantas halófilas del género Atriplex L.

Material adicional estudiado: ARGENTINA. Prov. La Rioja: Dpto. Famatina, orillas del rio Trancas, 13-I-1947, Hunziker 1830 (SI, CORD); Dpto. Felipe Varela, en los alrededores del Parque Nacional Talampaya, 23-IX-2017, Fabbroni \& Gauffin 1341 (MCNS). Prov. San Juan: Dpto. Iglesia; Colangüil, 2-II-1950, Castellanos 16828 (LIL); camino de Tudcum a Rodeo, 13-XII-1979, Cabrera et al. 31206 (SI); Dpto. Jáchal, Mayo 1986, Stramiglioli 19 (SI); río Gualcamayo, 14-II-2000, Kiesling, Wulff \& Tombesi 9489 (SI).

Observaciones. 1) La mayoría de las colecciones estudiadas fueron de ejemplares masculinos. Las únicas observaciones de ejemplares femeninos y en fruto fueron de los especímenes Hunziker 1830 (SI) y Castellanos 16828 (LIL).

2) Schinus talampaya ha sido muy confundida con S. polygama, a pesar de que las hojas son muy diferentes y particulares. Posiblemente esto pueda deberse a la polimorfía foliar ampliamente mencionada para $S$. polygama en las publicaciones $\mathrm{y}$ también por las ramas espinescentes y las flores imperfectas. 


\section{Fabbroniy M. A. Zapater Cano - Delimitación de S. polygama y descripción de nueva especie}

Algunos ejemplos de determinaciones erróneas en varias colecciones de herbario son: Cuezzo 2941 (LIL), Hunziker 1830 (SI), Stramiglioli 19 (SI) y Castellanos 16828 (LIL), como así también en publicaciones florísticas de la Cordillera de La Rioja (Hunziker, 1952), de la Flora de San Juan (Múlgura, 2003) donde la Fig. 83 ilustra el ejemplar de Márquez 114 (SI), de la Flora de Catamarca (Perea et al., 2007) en las tres fotografías de la página $245 \mathrm{y}$ en el listado florístico de la Sierra de Famatina (Barboza et al., 2016).

También fue confundida con S. longifolia (Lindl.) Speg., aparentemente por la longitud de sus hojas (Kiesling et al. 9489, SI). Sin embargo, la forma de la lámina en S. longifolia es larga y anchamente espatulada, oblonga, lanceolada y cortamente peciolada y atenuada hacia la base. Además, Schinus longifolia se distribuye en el sur de Brasil, Paraguay, Uruguay y en el litoral de la Argentina (Muñoz, 1990; 2000), por lo que presenta una distribución alopátrica en relación a $S$. talampaya.

Las diferencias morfológicas entre S. talampaya y S. polygama se presentan en la Tabla 1.

Como resultado del presente trabajo se presenta una clave que diferencia a $S$. polygama de $S$. fasciculata, especie con la que ha sido frecuentemente confundida en inventarios florísticos y en colecciones de herbario y también con $S$. talampaya.

\section{Tabla 1. Diferencias morfológicas entre S. talampaya y S. polygama.}

\begin{tabular}{|c|c|c|}
\hline Características & S. talampaya & S. polygama \\
\hline Lámina foliar & $\begin{array}{l}2,2-5,5 \times 0,1-0,4 \mathrm{~cm} \text {, lineares } \\
\text { a oblanceoladas, a veces } \\
\text { falcadas, uninervias, margen } \\
\text { entero }\end{array}$ & $\begin{array}{l}2-3,2 \times 0,4-1 \mathrm{~cm} \text {, obovadas, elípticas, } \\
\text { ovadas, pinatinervias, margen a veces } \\
\text { con } 2-3(4) \text { dientes en la mitad superior o } \\
\text { festoneado }\end{array}$ \\
\hline Pecíolo & 1-3 mm, glabro & 2-5 mm, glabro o con tricomas esparcidos \\
\hline Inflorescencias masculinas & Pseudoracimos congestos & Tirsos laxos \\
\hline $\mathrm{N}^{\circ}$ inflorescencias masculinas por nudo & 1 & $1-2(3)$ \\
\hline $\begin{array}{l}\text { Raquis y entrenudos de inflorescencias } \\
\text { masculinas }\end{array}$ & $\begin{array}{l}0,2-0,4 \mathrm{~cm}, \text { sin costillas, } \\
\text { cubierto semi a totalmente con } \\
\text { brácteas, entrenudos poco } \\
\text { visibles de } 0,2-0,6 \mathrm{~mm} \text { long. }\end{array}$ & $\begin{array}{l}1,2-2 \mathrm{~cm} \text {, con costillas, las brácteas no } \\
\text { cubren los entrenudos de } 0,5-2 \mathrm{~mm} \text { long. }\end{array}$ \\
\hline $\mathrm{N}^{\circ}$ flores por inflorescencia masculina & 2 a 9 & 11 a 38 \\
\hline $\mathrm{N}^{\circ}$ flores masculinas por nudo & 1 & $2-3(4)$ \\
\hline Pedicelo de flores masculinas & 1-2,4 mm long. & 2,6-4,6 mm long. \\
\hline Pedicelo basal & 0,4-1,2 mm long. & $1,1-2,4 \mathrm{~mm}$ long. \\
\hline Pedicelo apical & 0,6-1,2 mm long. & 1,5-2,2 mm long. \\
\hline Disco de abscisión & Poco notable no engrosado & Demarcado y engrosado \\
\hline $\begin{array}{l}\mathrm{N}^{\circ} \text { piezas periánticas de flores } \\
\text { masculinas }\end{array}$ & Pentámero & $\begin{array}{l}\text { Tetrámero y pentámero, a veces en el } \\
\text { mismo individuo }\end{array}$ \\
\hline Longitud de los pétalos & $1,8-2,2 \mathrm{~mm}$ & $2,5-3 \mathrm{~mm}$ \\
\hline Inflorescencias femeninas & $\begin{array}{l}\text { Raquis de } 0,1-0,28 \mathrm{~cm} \text { cubierto } \\
\text { por brácteas }\end{array}$ & $\begin{array}{l}\text { Raquis de } 0,7-1,4 \mathrm{~cm} \text { no cubierto por } \\
\text { brácteas }\end{array}$ \\
\hline $\mathrm{N}^{\circ}$ flores por inflorescencia femenina & $2-3$ & $10-19$ \\
\hline$N^{\circ}$ flores femeninas por nudo & 1 & $1-2(3)$ \\
\hline Pedicelo fructífero & $2,8-4,2 \mathrm{~mm}$ & $4-6,8 \mathrm{~mm}$ \\
\hline Fruto & $5,1-5,7 \times 5-6,4 \mathrm{~mm}$ & $3,5-4 \times 4-4,5 \mathrm{~mm}$ \\
\hline Distribución geográfica & $\begin{array}{l}\text { Endémica de Argentina } \\
\text { en La Rioja, San Juan y } \\
\text { probablemente Catamarca }\end{array}$ & $\begin{array}{l}\text { En Argentina (Mendoza) y en Chile desde } \\
\text { Atacama hasta Los Lagos }\end{array}$ \\
\hline
\end{tabular}




\section{Clave artificial para determinar Schinus talampaya, S. polygama y S. fasciculata}

1. Hojas lineares a oblanceoladas, a veces falcadas, uninervias, margen entero, de 2,2-5,5 x 0,1-0,4 cm. Pseudoracimos masculinos con 2-9 flores y los femeninos con 2-3 flores. S. talampaya

$1 '$. Hojas obovadas, elípticas, pinatinervias, margen a veces con 2-3 dientes apicales, de 0,9-3,2 x 0,4-1 cm. Tirsos y pseudoracimos masculinos con 10-38 flores y los femeninos con 7-19 flores.

2. Árbol y arbusto. Ramas espinescentes, agudas, levemente punzantes, con inserción variable de $45^{\circ}$ a $90^{\circ}$. Lámina obovada, elíptica, ovada, de 2-3,2 cm long., glabra. Tirsos masculinos con 2-3(4) flores por nudo; raquis de 1,2-2 cm, costillado, muy visible. Disco de abscisión demarcado y engrosado. Flores tetrámeras y pentámeras, a veces en el mismo individuo. Tirsos femeninos con 1-2 (3) flores por nudo; raquis claramente visible. Pedicelo fructífero de 4-6,8 $\mathrm{mm}$ long. Drupa obovoide.

S. polygama

2'. Arbustos. Ramas espinescentes fuertemente agudas y punzantes, de disposición espiralada e inserción generalmente a $90^{\circ}$. Lámina obovada raro elíptica, de 0,9-1,9 cm long., a veces pubescente. Pseudoracimos masculinos con 1 flor por nudo; raquis de 2,5-7(10) mm long., sin costillas, cubierto por brácteas. Disco de abscisión no evidente, diferente solo por coloración y pilosidad. Flores pentámeras. Pseudoracimos femeninos con 1 flor por nudo; raquis cubierto por brácteas. Pedicelo fructífero de 1,8-2 $\mathrm{mm}$ long. Drupa ovoide o esférica.

S. fasciculata

\section{Discusión}

La confusión de varias colecciones identificadas como $S$. polygama surgió inicialmente a partir de Cabrera (1938), autor que incorporó a la sinonimia de esta especie a distintos taxones, que en la actualidad son aceptados como entidades independientes como S. pilifera I. M. Johnston, S. longifolia (Lindl.) Speg. y S. praecox (Griseb.) Speg. (Barkley (1944, 1957). Además, la citó con una amplia distribución para la Argentina y Bolivia, Brasil, Chile y Uruguay. Cabrera (1938) también describió 11 taxones del rango Forma para $S$. polygama, teniendo en cuenta la morfología $\mathrm{y}$ pubescencia foliar; algunas de estas últimas actualmente son aceptadas bajo el rango de especie como es el caso de S. fasciculata (Griseb.) I. M. Johnst, S. johnstonii F.A. Barkley y $S$. marchandii F.A. Barkley. Posteriormente Barkley $(1944,1957)$ restringió la distribución de S. polygama a Bolivia, Chile central y solo para Mendoza en la Argentina al citar la var. parviflora (March.) Barkley. Para la Flora Fanerogámica Argentina, Muñóz (2000) confirmó la distribución geográfica publicada por Barkley (1944, 1957). Sin embargo y en el marco de esta investigación, surge que la distribución en Chile es más extensa, ya que ocupa diversos hábitats desde la costa hasta los pedemontes andinos (Rodríguez et al., 2008; 2018). Además, en la Argentina es probable que la distribución sea también más amplia en Mendoza según estudios ecológicos que mencionan poblaciones relictuales en la Precordillera mendocina (Roig \& Ambrosetti, 1971; Ambrosetti, 1972) y, eventualmente en otras provincias vecinas con hábitats similares por lo que cabría realizar mayores colecciones y revisiones de ejemplares en herbarios.

Bajo las identificaciones erróneas o la interpretación confusa en la Argentina y otros países y hábitats, se publicaron estudios de diferentes aspectos en poblaciones de Brasil, como de la morfoanatomía comparada entre $S$. polygama y Schinus terebentifolia Radii (Rodrígues et al., 2004), de la variación foliar (Fleig, 1985) y diversas investigaciones sobre los herbívoros agalladores (Damasceno et al., 2010; Gonçalves Dias et al., 2013a,b); sin embargo, S. polygama no es un integrante de la Flora brasilera. Entre estas confusiones, S. polygama fue designada como sinónimo de Schinus fasciculata por Cabrera (1938) y más recientemente por Demaio et al. $(2002,2015)$ para el Centro y Cuyo de Argentina.

Para la Flora chilena, Rodríguez et al. (2018) proponen la sinonimia de $S$. polygama var. parviflora con la variedad polygama. Sin embargo, el material original en el que se basó Barkley para describir S. polygama var. parviflora procede de Bolivia (Pentland 18) el cual mencionó el autor no haber revisado (Barkley, 1957: 57). Del estudio de fotografías de los dos especímenes 


\section{Fabbroniy M. A. Zapater Cano - Delimitación de S. polygama y descripción de nueva especie}

tipo de Pentland depositados en el Herbario P (P06634213, P06634217) provenientes de las localidades de Illimani y Chivisivi (Bolivia), surge que estos materiales en realidad se corresponden más apropiadamente con Schinus microphylla I. M. Johnst., citada para Perú por Barkley $(1944,1957)$ a 2500-3800 msnm y posteriormente reconocida por Silva Luz et al. (2019) para Bolivia. De este análisis resulta que la sinonimia propuesta por Rodríguez et al. (2018) no corresponde por la identificación errónea de los materiales originales.

Algunas de las características morfológicas que caracterizan a Schinus L. Sección Duvaua (Kunth) Marchand según Silva Luz et al. (2019) y que incluyen a $S$. polygama, difieren con las registradas en esta investigación, tal el caso de por ej. la existencia de flores tetrámeras y algunas pentámeras en la misma planta y la longitud del androceo normalmente inferior a la corola.

De acuerdo a Silva Luz et al. (2019), los pseudoracimos evolucionaron a partir de panículas, siendo plesiomórficos para el género Schinus, pero que sufrieron una reversión a panículas o tirsoides, los que aparecen varias veces dentro del linaje de hojas simples. Sin embargo, los botánicos que estudiaron el género como Cabrera (1938), Barkley (1944, 1957), Muñóz (2000) y Martínez Carretero (2009), no definieron claramente el concepto de pseudoracimo. Nuestros estudios de las inflorescencias basados en Rúa (1999) en el caso de $S$. talampaya, muestran que el denominado pseudoracimo es en realidad una ramificación cimosa de un racimo para formar un tirso (sin llegar a formarlo totalmente), considerando que se trata de un eje indeterminado con flores laterales cuyos ejes florales llevan prófilos (bractéolas) y que en su axila podrían desarrollar ejes florales de segundo orden (en este caso no formados). En el caso de $S$. polygama, los ejes florales se desarrollan en cimas y el conjunto resulta en un tirso o racimo de cimas.

Analizando la propuesta de Silva Luz et al. (2019), Schinus talampaya no pertenecería desde el punto de vista morfológico a la Sección Duvaua (Kunth) Marchand como S. polygama, sino más bien sus caracteres florales concuerdan más adecuadamente con algunos taxones de la Sección Pilifera Silva Luz \& J. D. Mitch., por sus flores pentámeras, raquis corto cubierto total o parcialmente por brácteas rojizas y con una sola flor por nudo. De algún modo, esto puede concordar con Silva Luz et al. (2019) que advierten sobre la existencia de especies crípticas con la posibilidad de que la Sección Pilifera fuera un complejo de especies que requeriría una nueva revisión taxonómica más detallada.

\section{Conclusión}

Nuestros resultados muestran que las dos especies estudiadas son muy diferentes e inclusive pertenecen a secciones distintas. Se aportan numerosos caracteres que permiten una identificación más precisa de $S$. polygama, muchas veces confundida con otras especies espinescentes y, se actualiza su distribución geográfica y biogeográfica. La identificación de un taxón novedoso, S. talampaya, resulta un interesante aporte a Schinus Sect. Pilifera, lo que supone una redefinición de las características morfológicas del grupo y por ende su circunscripción taxonómica en el contexto de la sistemática infragenérica.

\section{Contribución DE LOS AUTORES}

MF y AZ diseñaron y realizaron la investigación; MF coleccionó el material de campo. Ambas autoras participaron en la escritura del manuscrito.

\section{Agradecimientos}

A los revisores cuyos aportes mejoraron el presente trabajo. Nuestro reconocimiento a los curadores de los herbarios consultados CTES, LIL, MCNS, MERL y SI por las atenciones recibidas y préstamo del material de estudio; al director del Herbario Real Jardín Botánico por el envío de imágenes digitalizadas; al Dr. Manuel Belgrano del Instituto Darwinion, quién nos ayudó con fotografías de especímenes de $S$. polygama del SI de distintas provincias en época de restricciones sanitarias; al Ing. Lázaro Novara por la traducción del protólogo en latín; al Dr. Federico Robiatti por la elaboración del mapa y el formato de las figuras; a la Ing. María del C. Otero por la ilustración, a la Dra. María M. Arbo por la traducción al inglés; al Dr. Pedro Jiménez-Mejías por la bibliografía de los tipos de Cavanillies y el resumen en inglés; a la Lic. 
Evangelina Lozano por el formato de las figuras y al Ing. José M. Gauffín por la logística en los viajes de campo. Este trabajo se realizó con el financiamiento del Consejo de Investigación de la Universidad Nacional de Salta en el marco de los Proyectos A 2283 y B 2557.

\section{Bibliografía}

AMBROSETTI, J. A. 1972. Especies interesantes en la ordenación de la cuenca Papagallos, I. Deserta 2: 207-237.

ARECHAVALETA, J. 1901. Flora Uruguaya. XXXI Anacardiáceas. Anales Mus. Nac. Montevideo 3(7): 294-301.

BARBOZA, G. E., J. J. CANTERO, F. E. CHIARINI, J. CHIAPELLA, S. FREIRE, C. O. NUÑEZ, V. PALCHETTI \& L. ARIZA ESPINAR. 2016. Vascular plants of Sierra de Famatina (La Rioja, Argentina): an analysis of its biodiversity. Phytotaxa 248: 1-123 http://dx.doi.org/10.11646/phytotaxa.248.1.1

BARKLEY, F. A. 1944. Schinus L. Brittonia 5: 160-198.

BARKLEY, F. A. 1957. A study of Schinus L. Lilloa 28: $5-110$.

BURCKHARDT, D. \& Y. BASSET. 2000. The jumping plant-lice (Hemiptera, Psylloidea) associated with Schinus (Anacardiaceae): systematics, biogeography and host plant relationships. J. Nat. Hist. 34: 57-155. https://doi.org/10.1080/002229300299688

CABRERA, A. L. 1938. Revisión de las Anacardiáceas Austroamericanas. Rev. Mus. La Plata, Bot. 2: 3-64.

CABRERA, A. L. 1976. Regiones Fitogeográficas de la República Argentina. Enciclopedia Argentina de Agricultura y Jardinería, 2a ed. ACME, Buenos Aires.

CABRERA, A. L. \& A. WILLINK. 1973. Biogeografía de América Latina. Monografías de la OEA, Serie de Biología, Washington DC.

CAVANILlES, A. J. 1794. Icones et descriptiones plantarum, quae aut sponte in Hispania crescunt, aut in hortis hospitantur 3. Madrid.

CORPORACIÓN CULTIVA. 2018. Informe de avance $N^{\circ}$ 6: Proyecto Reforestación Parque Cerros de Renca. Plan de compensación de emisiones y material particulado resuspendido mediante la creación y mantención de áreas verdes para cumplimiento de RCA 346/2006. Renca, Chile.

CORTEZ-ECHEVERRÍA, J. 2016. Guías de campo de Fray Jorge. Tomo II. Flora: Bosque y Matorral
Semiárido. Centro de Estudios Avanzados en Zonas Áridas (CEAZA). La Serena, Chile.

DAMASCENO, F. C., K. P. PRIMIERI, J. L. GONÇALVES \& C.ALCARAZ. 2010. Changes in the volatile organic profile of Schinus polygamus (Anacardiaceae) and Baccharis spicata (Asteraceae) induced by galling psyllids. J. Brazil Chem. Soc. 21: 556-563. https://doi.org/10.1590/S0103-50532010000300023

DE CANDOLLE, A.P. 1825. Prodomus systematis naturalis regni vegetabilis. Pars secunda. Paris: Treuttel \& Wiirtz, Paris.

DEMAIO, P., U. O. KARLIN \& M. MEDINA. 2002. Árboles Nativos del Centro de Argentina. L.O.L.A., Buenos Aires.

DEMAIO, P., U. O. KARLIN \& M. MEDINA. 2015. Árboles Nativos de Argentina: Centro y Cuyo. Ecoval Ediciones, Córdoba.

DIAS, G. D., B. G. FERREIRA, G. R. P. MOREIRA \& R. M. S. ISAIAS. 2013a. Developmental pathway from leaves to galls induced by a sap-feeding insect on Schinus polygamus (Cav.) Cabrera (Anacardiaceae). An. Acad. Bras. Cienc. 85: 187-200. https://doi.org/10.1590/S0001-37652013000100010

DIAS, G. G., G. R. P. MOREIRA, B. G. FERREIRA \& R. M. S. ISAIAS. 2013b. Why do the galls induced by Calophya duvauae Scott on Schinus polygamus (Cav.) Cabrera (Anacardiaceae) change color? Biochem Syst Ecol. 48: 111-122.

http://dx.doi.org/10.1016/j.bse.2012.12.013

ENGLER, H. G. A. 1876. Anacardiaceae. En: MARTIUS, C. F. P. VON \& A.W. EICHLER (eds.), Flora brasiliensis 12: 367-418.

ERAZO, S., C. DELPORTE, R. NEGRETE, R. GARCÍA, M. ZALDÍVAR, G. ITURRA, G., E. CABALLERO, J. L. LÓPEZ \& N. BACKHOUSE. 2006. Constituents and biological activities of Schinus polygamus. $J$. Ethnopharmacol. 107: 395-400. https://doi.org/10.1016/j.jep.2006.03.028

FLEIG, M. 1985. Análise da variação foliar de Schinus polygamus (Cav.) Cabrera (Anacardiaceae). Iheringia 33: 3-16.

FRENGUELLI, J. 1937. Investigaciones geológicas en la zona salteña del valle de Santa María. Ed. Coni, Buenos Aires.

GARILLETI, R. 1993. Herbarium cavanillesianum seu enumeratio plantarum exsiccatarum aliquo modo ad novitates cavanillesianas pertinentium, quae in Horti Regii Matritensis atque Londinensis Societatis Linnaeanae herbariis asservantur. Fontqueria 38: 6-248. 


\section{Fabbroniy M. A. Zapater Cano - Delimitación de S. polygama y descripción de nueva especie}

GUEDES GARCÍA, L. M., N. AgUILERA, B. G. FERREIRA, J. BECERRA, V. HERNÁNDEZ \& R. M. S. ISAIAS. 2018. Anatomical and phenological implications of the relationship between Schinus polygama (Cav.) (Cabrera) (Anacardiaceae) and the galling insect Calophya rubra (Blanchard) (Hemiptera: Psylloidea). Plant Biology 20: 507-515. https://doi.org/10.1111/plb.12696

HOFFMANN, A. 1995. Flora silvestre de Chile: zona central: una guía ilustrada para la identificación de las especies vegetales más frecuentes. Fundación Claudio Gay, Chile.

HUNZIKER, J. H. 1952. Las comunidades vegetales de la Cordillera de La Rioja. Rev. Invest. Agrop. 6: 167-196.

JOHNSTON, I. M. 1938. Schinus polygamus (Cav.) comb. nov. J. Arnold Arbor. 19: 254-256.

KUNTH, C. S. 1824. Nova Genera et Species Plantarum 2. Ann. Sci. Nat. 2: 340-341.

MACBRIDE, J. F. 1951. Anacardiaceae. En: MACBRIDE, J. F. (ed.), Flora of Perú Bot. Ser. 13 (3A/1): 238-258.

MARCHAND, N. L. 1869. Révision $d u$ groupe des Anacardiacées. Balliere, Sons, Paris.

MARTÍNEZ CARRETERO. E. 2009. Anacardiaceae Lindl. Multequina 18: 28-39.

MÉNDEZ, E. 2011. La vegetación de los altos Andes. El flanco oriental del Cordón del Portillo (Tunuyán, Mendoza, Argentina). Bol. Soc. Argent. Bot. 46: 317-353.

MORENO, N. P. 1984. Glosario Botánico Ilustrado. Compañía Editorial Continental, Distrito Federal, México.

MORRONE, J. J. 2004. La zona de transición sudamericana: caracterización y relevancia evolutiva. Acta Entomol. Chil. 28: 41-50.

MÚLGURA, M. E. 2003. Anacardiaceae. En: KIESLING, R. (ed.), Flora de San Juan 2: 86-90.

MUÑOZ, J. D. 1990. Anacardiaceae. En: SPICHIGER, R. \& L. RAMELLA (eds.), Flora del Paraguay. Missouri Bot. Gard. \& Conservatoire et Jardin Botaniques de la Ville de Geneve 14: 7-84.

MUÑOZ, J. de D. 2000. Anacardiaceae. En: HUNZIKER, A. T. (ed.), Fl. Fanerog. Argent. 65: 1-10.

ORTEGA, C. G. 1798. Novarum, aut rariorum plantarum Horti Reg. Botan. Matrit.: descriptionum decades, cum nonnullarum iconibus, 8: 102.

OYARZÁBAL, M., J. CLAVIJO, L. OAKLEY, F. BIGANZOLI, P. TOGNETTI, I. BARBERIS, H. M. MATURO, R. ARAGÓN, P. I. CAMPANELLO,
D. PRADO, M. OESTERHELD \& R. J. C. LEÓN. 2018. Unidades de Vegetación de la Argentina. Ecol. Austral 28: 40-63.

https://doi.org/10.25260/EA.18.28.1.0.399

PEREA, M. C., G. PEDRAZA \& J. LUCEROS. 2007. Relevamiento de la flora arbórea autóctona en la provincia de Catamarca. San Fernando del Valle de Catamarca, Catamarca. $1^{\text {a }}$ ed. Consejo Federal de Inversiones.

QUANTUM GIS GEOGRAPHIC INFORMATION SYSTEM. 2018. Open Source Geospatial Foundation Project. Disponible en: http://qgis.osgeo. org [Acceso: 12 octubre 2020].

RODRIGUES, D. M., J. M. S. DE OLIVEIRA, J. E. DE ARAUJO \& T. H. MARIA. 2004. Comparação de desenvolvimento inicial do rudimento seminal em Schinus terebinthifolius Raddi e Schinus polygamus (Cav.) Cabr. (Anacardiaceae). Revista de Iniciação Cientifica da ULBRA 3: 61-72.

RODRÍGUEZ, R., J. GRAU, C. BAEZA \& A. DAVIES. 2008. Lista comentada de las plantas vasculares de Los Nevados de Chillan, Chile. Gayana Bot. 65: 153-197.

RODRÍGUEZ, R., C. MARTICORENA, D. ALARCÓN, C. BAEZA, L. CAVIERES, V. L. FINOT, N. FUENTES, A. KIESSLING, M. MIHOC, A. PAUCHARD, E. RUIZ, P. SANCHEZ \& A. MARTICORENA. 2018. Catálogo de las plantas vasculares de Chile. Gayana Bot. 75: 1-430. http://dx.doi.org/10.4067/S0717-66432018000100001

ROIG, F. A. \& J.A. AMBROSETTI. 1971. Investigaciones climáxicas I. Restos de un estrato arbóreo bajo de Schinus polygamus en la Precordillera de Mendoza. Deserta 2: 115-130.

RÚA, G. H. 1990. Inflorescencias: bases teóricas para su análisis. Sociedad Argentina de Botánica, Buenos Aires.

SÁIZ, F. \& C. NÚÑEZ. 1997. Estudio ecológico de las cecidias del género Schinus, especialmente las de hoja y de rama de $S$. polygamus y Schinus latifolius (Anacardiaceae) en Chile Central. Acta Entomol. Chil. 21, 39-59.

STEIBEL, P. E. \& TROIANI, H. O. 2008. La identidad de Schinus fasciculatus var. arenicola y rehabilitación de S. sinuatus (Anacardiaceae). Bol. Soc. Argent. Bot. 43: 157-166.

SILVA LUZ, C. L. DA. 2017. Filogenia e sistematica de Schinus L. (Anacardiaceae), com revisão de um clado endêmico das matas nebulares andinas. Tesis Doctoral. Instituto de Biociências da Universidade de São Paulo, Brasil. 
SILVA LUZ, C. L. DA, J. R. PIRANI, J. D. MITCHEL, D. DALY, N. DO VALLE CAPELliA, D. DEMARCO, S. K. PELL \& G. M. PLUNKETTD. 2019. Phylogeny of Schinus L. (Anacardiaceae) with a new infrageneric classification and insights into evolution of spinescence and floral traits. Mol. Phylogenetics Evol. 133: 302-351. https://doi.org/10.1016/j.ympev.2018.10.013

THIERS, B. Continuously updated. Index Herbariorum: A global directory of public herbaria and associated staff. New York Botanical Garden's Virtual Herbarium. http://sweetgum.nybg.org/science/ih. [Acceso: 15 noviembre 2020].
TURLAND, N. J., J. H. WIERSEMA, F. R. BARRIE, W. GREUTER, D. L. HAWKSWORTH, P. S. HERENDEEN, S. KNAPP, W.-H. KUSBER, D. Z. LI, K. MARHOLD, T. W. MAY, J. MCNEILL, A. M. MONRO, J. PRADO, M. J. PRICE \& G. F. SMITH (eds.). 2018. Código Internacional de Nomenclatura para algas, hongos y plantas (Código de Shenzhen). Traducción al español por Greuter, W. \& R. Rankin Rodríguez, Fundación Herbario Greuter, Berlín, Alemania y Universidad Técnica de Cotopaxi, Latacunga, Ecuador.

WILHELM-MÖSBACH, E. 1992. Botánica indígena de Chile. Ed. Andrés Bello, Santiago, Chile. 